\title{
A 3-day regimen with azithromycin $1.5 \%$ eyedrops for the treatment of purulent bacterial conjunctivitis in children: efficacy on clinical signs and impact on the burden of illness
}

\author{
This article was published in the following Dove Press journal: \\ Clinical Ophthalmology \\ 20 April 2015 \\ Number of times this article has been viewed
}

\section{Dominique Bremond- \\ Gignac ${ }^{1,2}$ \\ Riadh Messaoud ${ }^{3}$ \\ Sihem Lazreg ${ }^{4}$ \\ Claude Speeg-Schatz ${ }^{5}$ \\ Didier Renault ${ }^{6}$ \\ Frédéric Chiambaretta ${ }^{7,8}$ \\ On behalf of the \\ Azithromycin Pediatric \\ Study Group \\ 'Ophthalmology Department, Centre St Victor, University Hospital of Amiens, Picardie Jules Verne University, Amiens, France; ${ }^{2} \mathrm{CNRS}$ FR3636, Paris V University, France; ${ }^{3}$ Ophthalmology Department, Tahar Sfar University Hospital, Mahdia, Tunisia; ${ }^{4}$ Dar El Beida, Blida, Algeria; ${ }^{5}$ Ophthalmology Department, University Hospital of Strasbourg, Strasbourg, France; ' 6 Laboratoires THÉA, Clermont-Ferrand, France; ${ }^{7}$ Ophthalmology Department, University Hospital of Clermont- Ferrand, Gabriel Montpied Hospital, Clermont-Ferrand, France; ${ }^{8} \mathrm{EA}$ 728I R2D2, Auvergne University, Clermont-Ferrand, France}

Correspondence: Dominique BremondGignac

Service d'Ophtalmologie, Centre Saint Victor, CHU d'Amiens, 354 Bd de Beauville, 80054 Amiens, France

Tel +33 322824108

Fax +33 322824061

Email bremond.dominique@chu-amiens.fr
Purpose: To compare the efficacy of azithromycin $1.5 \%$ versus tobramycin $0.3 \%$ eyedrops on clinical ocular signs and symptoms of bacterial conjunctivitis in children and to assess the parents' satisfaction regarding the dosing regimen.

Patients and methods: An international, multicenter, randomized, investigator-masked, controlled clinical trial conducted in children (1 day to 18 years old) with bulbar conjunctival hyperemia and purulent discharge. Azithromycin $1.5 \%$ was administered as 1 drop twice daily for 3 days, and tobramycin $0.3 \%$ as 1 drop every 2 hours for 2 days, then 4 times daily for 5 days.

Results: A total of 286 patients (mean age: 3.2 years) were enrolled. In children with bacteriologically positive cultures $(\mathrm{N}=203)$, azithromycin produced a significantly greater improvement in conjunctival discharge $(P<0.01)$ and a trend $(P=0.054)$ toward improvement in conjunctival hyperemia at day 7 than did tobramycin. Complete resolution of conjunctival discharge was significantly more frequent at day 3 on azithromycin than tobramycin $(P=0.005)$. More parents found azithromycin easier to use (in terms of treatment duration, total number of instillations, instilling drops during the day, and difficulty in performing daily activities) than tobramycin. Conclusion: The azithromycin $1.5 \%$ regimen produced a rapid resolution of cardinal signs of purulent bacterial conjunctivitis with a more convenient dosage regimen. Such improved convenience is likely to improve compliance and lessen the burden of illness for patients and carers.

Keywords: acceptability, azithromycin, bacterial conjunctivitis, children, compliance, topical antibiotics, QOL

\section{Introduction}

Bacterial conjunctivitis is one of the most common eye infections, accounting for $70 \%-80 \%$ of all cases of infectious conjunctivitis in children. ${ }^{1-3}$ It is mainly characterized by purulent discharge, moderate diffuse conjunctival hyperemia, and burning or stinging sensations. Follicular reaction of palpebral conjunctiva, eyelid erythema, and swelling are also common clinical signs. ${ }^{4,5}$ In preschool- and school-age children, Haemophilus influenzae and Streptococcus pneumoniae are the most common pathogens, and thus quite different from the bacteriological profile in adults in whom Staphylococcus epidermidis, coagulase-negative staphylococcus, and S. aureus pathogens are predominantly found. ${ }^{5-8}$

Although bacterial conjunctivitis generally resolves spontaneously in a few days, there is broad agreement that topical antibiotics are worthwhile, particularly in moderate 
to severe infection, to shorten the course of the illness and allow the child to return to school and other daily activities. ${ }^{9,10}$ Choice of antibiotic is usually informed predominantly by the clinician's judgment since the results of microbial tests are generally not available at the initial consultation.

Azithromycin 1.5\% ocular solution is approved for the treatment of purulent bacterial conjunctivitis in adults as well as in children (including infants and neonates) and has a shorter and less frequent therapeutic scheme than conventional antibiotic eyedrops. ${ }^{11}$ The 3-day twice-daily regimen with azithromycin $1.5 \%$ ocular solution is much shorter and requires less frequent daily administrations. In addition, azithromycin $1.5 \%$ eyedrops have been recently shown to provide a more rapid clinical cure than tobramycin $0.3 \%$ eyedrops in the treatment of purulent bacterial conjunctivitis in the pediatric population. ${ }^{12}$ Although several topical antibiotics are employed in this indication in children, tobramycin $0.3 \%$ was chosen as comparator because it can be considered a standard of care and has been widely investigated. ${ }^{13-15}$ Although other twice-daily preparations such as fusidic acid are available, they are generally formulated as an ophthalmic gel that is somewhat less convenient for use in young children. Moreover, tobramycin has been used as comparator in other similar studies. ${ }^{16,17}$

This multicenter, randomized, controlled clinical trial was specifically conducted in children and included a large proportion of neonates and infants $(55.9 \%$ and $54.5 \%$ of the azithromycin and tobramycin groups, respectively, were less than 2 years old); azithromycin $1.5 \%$ eyedrops produced a statistically superior clinical cure rate compared with tobramycin $0.3 \%$ at day 3 (47.1\% vs $28.7 \%$ respectively, $P=0.013)$, a statistically noninferior clinical cure rate at day 7 (89.2\% vs $78.2 \%$ respectively), and similar bacteriological resolution rates at day 7 (89.8\% vs $87.2 \%$ respectively). ${ }^{12}$

In addition to bacteriology and cure rates, the aforementioned study collected data on disease outcome, in terms of clinical signs and ocular symptoms, and the satisfaction and acceptability of treatment with topical antibiotics. Since there is currently almost no data on the burden of the disease and its management from a patient and parent perspective, the objective of the current report is to present this previously unreported data on the comparison of azithromycin eyedrops with tobramycin eyedrops on these parameters.

\section{Methods}

\section{Study design}

The study was a multicenter, international, randomized, investigator-masked, parallel-group study to compare the efficacy and safety of azithromycin $1.5 \%$ eyedrops (Azyter ${ }^{\circledR}$, Laboratoires Théa, Clermont-Ferrand, France) versus tobramycin $0.3 \%$ (Tobrex $^{\circledR}$, Laboratoires Alcon, RueilMalmaison, France) in pediatric patients. The methodology has been previously reported. ${ }^{10}$

A total of 21 investigational centers in 8 countries (Algeria, France, Germany, Italy, Poland, Portugal, Romania, and Tunisia) participated. The study was carried out in accordance with Good Clinical Practice, the Declaration of Helsinki, and local regulations and registered under the reference number NCT01155999 (http://clinicaltrials.gov). Ethics committee approvals were obtained in each country prior to enrolling any patient. Written informed consent was obtained from parents/guardians.

\section{Subjects}

Infants, children, and adolescents with purulent bacterial conjunctivitis aged from 1 day to less than 18 years were included. Purulent bacterial conjunctivitis was clinically defined by the presence of both bulbar conjunctival hyperemia and purulent discharge in at least one eye.

\section{Treatments}

On day 0 , eligible patients were randomized to azithromycin $1.5 \%, 1$ drop twice daily (morning and evening) for 3 days, or tobramycin $0.3 \%, 1-2$ drops every 2 hours while awake during the first 2 days (up to 8 times/day), then 1 drop 4 times/ day for the following 5 days. Randomization was stratified by age group (patients aged from 1 day of life to 4 years old, patients aged from 4 to 12 years old, patients aged from 12 to 18 years old). The randomization was by random permuted blocks with a block-size of 4 . This method ensured that the number of patients randomized to each treatment group was similar in each age group.

Compliance was monitored by questioning of patients during visits at day 3 and day 7 and by accounting of used and unused administration units.

\section{Ocular examination}

Clinical signs of bacterial conjunctivitis were assessed for each eye under slit-lamp examination at day 0 , day 3 , and day 7 .

\section{Ocular signs}

Cardinal signs (bulbar conjunctival hyperemia and conjunctival purulent discharge) and other signs (folliculo-papillary reactions of the palpebral conjunctiva, eyelid erythema, eyelid edema) were graded using 4-point ordinal scales as described previously. ${ }^{10}$ 
A conjunctival sample was obtained from each eye at day 0 and day 7. Bacteriologic samples were considered positive when isolated bacteria were above the threshold defined by the modified Cagle's classification. ${ }^{18}$

\section{Global efficacy assessment by the investigator}

The investigator assessed the treatment's global efficacy at day 3 and day 7 using a 4-point scale (very satisfactory, satisfactory, not very satisfactory, unsatisfactory).

\section{Self-administered questionnaires}

A standardized questionnaire, completed with evaluation by the patient or legal guardian, was used to collect the following information:

- Treatment efficacy: global assessment of efficacy at the end of therapy (graded as very satisfactory, satisfactory, not very satisfactory, or unsatisfactory), latency before improvement was felt $(1,2,3$, or more than 3 days).

- Ease of treatment use: appraisal of treatment duration (rated as very satisfactory, satisfactory, not very satisfactory, or unsatisfactory), easiness of performing instillations during the day and of respecting the prescribed number of instillations (rated as "very easy", "easy", "not very easy," or "difficult").

- Burden of illness: appraisal of the difficulty experienced in performing daily activities (including absence from work, school, or nursery; rated as never, rarely, sometimes, or constantly).

The questionnaires were returned at the end of treatment (day 3 for the azithromycin group, day 7 for the tobramycin group).

\section{Statistics}

Ocular signs, ocular symptoms, and global efficacy assessments were analyzed for both eyes in randomized patients with bacterial conjunctivitis confirmed by positive microbiological samples (microbiologically positive full analysis set [MFAS]). The acceptability criteria (ease of treatment use and impact on daily life) were assessed in the FAS (all randomized patients who instilled at least one drop of treatment). Descriptive statistics were provided overall and by age category (expressed as mean values \pm standard deviation [SD]). Missing data were handled using a last available assessment carried forward approach. For treatment group comparison, ordinal variables were analyzed using the exact Cochran-Mantel-Haenzel test, stratified by age group. Analysis of the total symptom score was performed using a mixed model for repeated measures. Comparisons were performed two-sided at the $5 \% \alpha$ level of significance.

\section{Results}

\section{Patient disposition and demographics}

The FAS population comprised 282 patients (146 in the azithromycin group and 136 in the tobramycin group). Age ranged from 1 day to 17 years (mean of $3.2 \pm 3.8$ years), and 148 patients $(52.5 \%)$ were less than 2 years old. A total of 203 patients (102 on azithromycin and 101 on tobramycin) had documented purulent bacterial conjunctivitis with a positive microbiological sample at day 0 (MFAS population). Of the 203 patients with bacteriologically confirmed bacterial conjunctivitis, 112 (55\%) were younger than 24 months old. Demographic data for the full analysis set are provided in Table 1 . There were no statistically significant differences between groups in baseline characteristics including age, sex ratio, ocular signs, and symptoms in both eyes, as described previously. ${ }^{12}$

The rate of return of questionnaires was $57.5 \%$ in the azithromycin group and $53.6 \%$ in the tobramycin group. Questionnaire return rates were slightly higher among parents of children younger than 2 years $(60.5 \%$ and $58.3 \%$ respectively).

Table I Patient demographics (full analysis set)

\begin{tabular}{|c|c|c|c|}
\hline & Azithromycin $(\mathrm{N}=146)$ & Tobramycin $(\mathrm{N}=136)$ & All patients $(\mathbf{N}=\mathbf{2 8 2})$ \\
\hline \multicolumn{4}{|l|}{ Sex } \\
\hline Male, N (\%) & 70 (47.9) & $68(50.0)$ & I 38 (48.9) \\
\hline Female, N (\%) & $76(52.1)$ & $68(50.0)$ & I44 (5I.I) \\
\hline \multicolumn{4}{|l|}{ Age (yr) } \\
\hline Mean \pm SD & $3.06 \pm 3.40$ & $3.52 \pm 4.17$ & $3.28 \pm 3.79$ \\
\hline \multicolumn{4}{|c|}{ Age category, N (\%) } \\
\hline 0 to $<24 \mathrm{mo}$ & $76(52.1)$ & $72(52.9)$ & $148(52.5)$ \\
\hline $24 \mathrm{mo}$ to $<4 \mathrm{yr}$ & $25(17.1)$ & $19(14.0)$ & $44(15.6)$ \\
\hline $4 \mathrm{yr}$ to $<12 \mathrm{yr}$ & $42(28.8)$ & $35(25.7)$ & $77(27.3)$ \\
\hline $12 y r$ to $<18 y r$ & $3(2.1)$ & $10(7.4)$ & $13(4.6)$ \\
\hline
\end{tabular}

Abbreviations: mo, months; $y r$, years. 
No subjects were excluded for inadequate compliance. At day 3, 9 out of 76 (11.8\%) subjects in the azithromycin group and 1 out of $71(1.4 \%)$ subjects in the tobramycin group reported that not every treatment was administered as planned.

Four patients in each group had microbiologically positive conjunctivitis, but did not have both cardinal clinical signs. These patients are included in the MFAS set analyzed here.

\section{Ocular examination}

\section{Cardinal signs}

The evolution of the severity of cardinal signs of purulent bacterial conjunctivitis is presented for the worse eye in Figure 1. At day 3, a significantly greater improvement in conjunctival discharge (absent in $68.3 \%$ of patients on azithromycin vs $48.5 \%$ on tobramycin; $P=0.005$ ) and a trend for a greater improvement in bulbar conjunctival hyperemia (absent in $55.4 \%$ vs $43.6 \%$ respectively; $P=0.054$ ) was shown in the azithromycin group. At day 7 , the clinical efficacy of azithromycin eyedrops was significantly higher compared with tobramycin eyedrops for both cardinal signs $(P=0.014$ for bulbar conjunctival hyperemia, and $P=0.028$ for purulent conjunctival discharge).

\section{Global efficacy assessment by the investigator}

Figure 2 shows that azithromycin eyedrops were significantly more effective than were tobramycin eyedrops in terms of the global efficacy assessment by the investigator at day 3 $(P=0.011)$ and day $7(P=0.003)$. The proportion of patients for whom the global efficacy was rated as "very satisfactory" was higher for azithromycin than for tobramycin at day 3 (60.6\% vs $42.0 \%$ respectively) and day 7 (76.8\% and 55\% respectively).

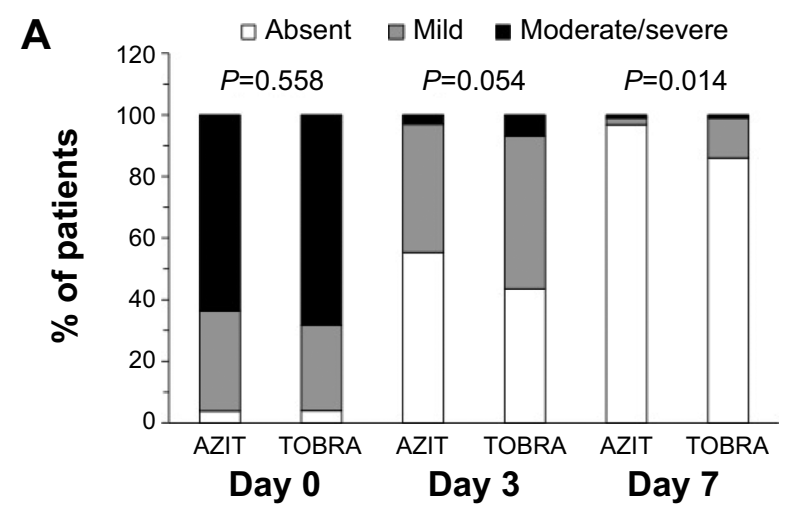

Among the subgroup of patients aged less than 24 months, the proportion with a global efficacy assessment of "very satisfactory" was again higher in the azithromycin group than in the tobramycin group $(52.6 \%$ vs $31.5 \%$ respectively at day 3 and $73.6 \%$ vs $44.4 \%$ respectively at day 7 ).

\section{Patient/guardian self-administered questionnaire}

Improvement during the first 2 days of treatment was significantly higher in azithromycin-treated patients than in those receiving tobramycin $(86.0 \%$ vs $48.2 \%$ respectively, $P=0.002$, Figure 3). At the end of therapy, assessment of the overall efficacy was similar in both groups (judged as very satisfactory or satisfactory by $89.2 \%$ of azithromycin-treated patients and $87.5 \%$ of tobramycin-treated patients, $P=0.933$ ). The duration of treatment was rated as "very satisfactory" or "satisfactory" by $95.0 \%$ versus $76.7 \%$ of azithromycinand tobramycin-treated patients respectively $(P<0.001$; Figure 4A). These rates included $69.1 \%$ of patients in the azithromycin group judging it as "very satisfactory," versus only $20.5 \%$ in the tobramycin group.

Instillation of drops during the day was rated as "very easy" significantly more commonly in patients on azithromycin than in those on tobramycin $(65.2 \%$ vs $13.3 \%$ respectively, $P<0.001$; Figure 4B). A significantly lower proportion of azithromycin- than tobramycin-treated patients considered it either "not very easy" or "difficult" to comply with the prescribed number of instillations $(2.4 \%$ vs $40.0 \%$ respectively, $P<0.001$; Figure 4C). Finally, the proportion of patients who never found difficulty in performing usual daily activities during treatment was significantly higher in the azithromycin group compared with the tobramycin group $(84.0 \%$ vs $54.8 \%$ respectively, $P<0.001$; Figure 4D).

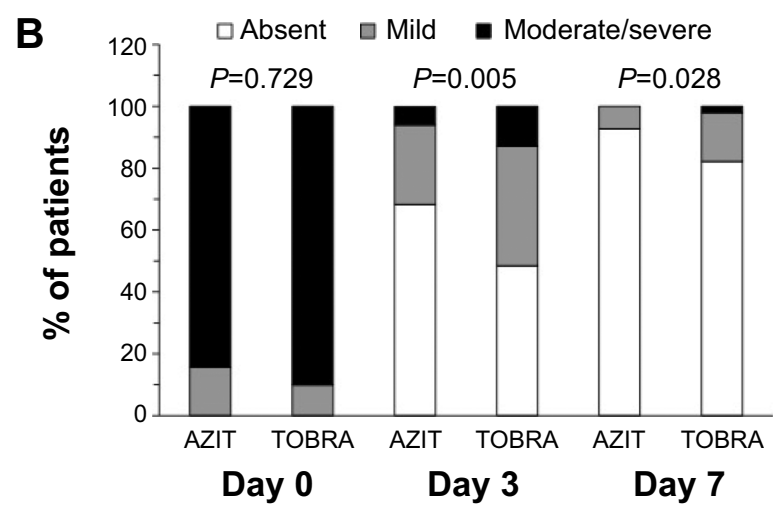

Figure I Evolution of cardinal signs of bacterial conjunctivitis.

Notes: (A) Bulbar conjunctival hyperemia; (B) purulent conjunctival discharge. Microbiologically positive full analysis set. Azithromycin group: (AZIT): N=I02 on day 0, $\mathrm{N}=10 \mathrm{I}$ on day $3, \mathrm{~N}=96$ on day 7 ; tobramycin group (TOBRA): $\mathrm{N}=10 \mathrm{I}$ on day 0 , day 3 , and day 7 . Data presented from the worse eye. 
A

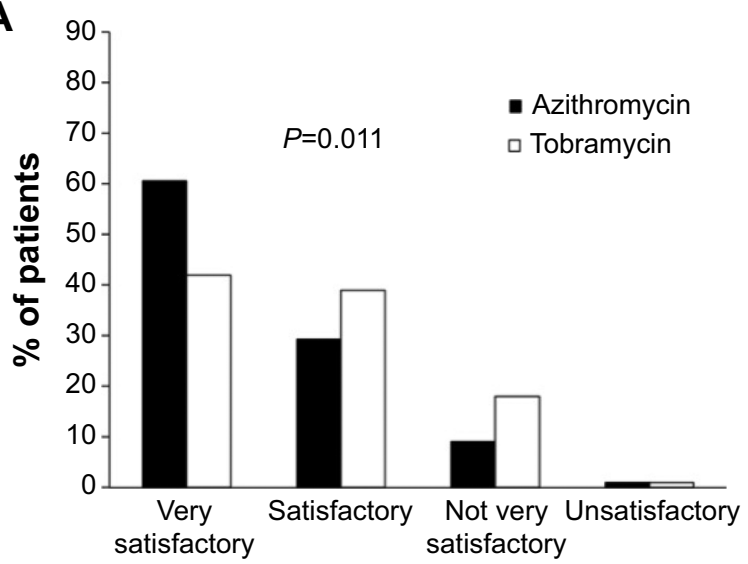

B

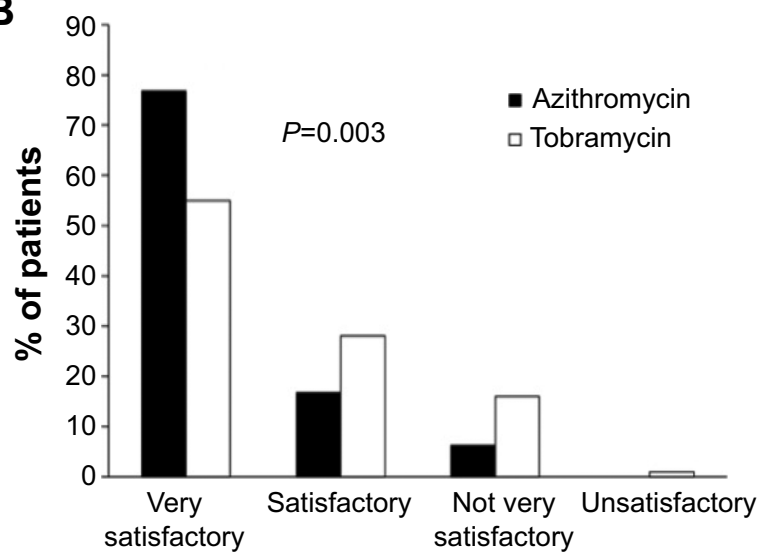

Figure 2 Global efficacy assessment by the investigator.

Notes: (A) Day 3; (B) day 7. Microbiologically positive full analysis set. Azithromycin group: N=99 at day 3 and $\mathrm{N}=95$ at day 7 ; tobramycin group: $\mathrm{N}=100$ on day 3 and day 7 . Data presented from the worse eye.

\section{Results in infants}

In 112 infants (aged less than 24 months) bulbar conjunctival hyperemia was absent in 34 out of 57 (59.6\%) patients in the azithromycin group versus 25 out of $55(45.5 \%)$ patients in the tobramycin group at day 3 , and in $98.1 \%$ and $78.2 \%$ of patients respectively at day 7. Purulent conjunctival discharge was absent in 33 out of 57 (57.9\%) patients in the azithromycin group at day 3 versus 21 out of 55 (38.2\%) patients in the tobramycin group, and in $88.7 \%$ and $70.9 \%$ respectively at day 7 .

Results of the questionnaire responses in infants were generally similar to those in the group as a whole, with global efficacy, delay until improvement, treatment duration, ease of instillation, ease of respecting instillation frequency, and difficulty of performing daily activities all showing advantages for azithromycin over tobramycin (Table 2).

\section{Discussion}

Although both treatments were effective, azithromycin resulted in more frequent and more rapid improvement of

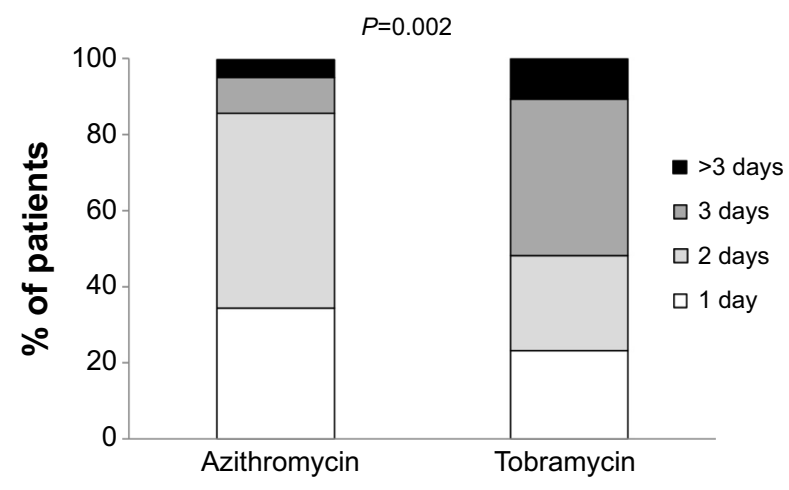

Figure 3 Number of days that an improvement was felt.

Notes: Microbiologically positive full analysis set; 65 patients in the azithromycin group and 56 patients in the tobramycin group. both conjunctival discharge and bulbar hyperemia than did tobramycin among children with bacteriologically proven bacterial conjunctivitis. Global efficacy, as assessed by the investigator, was significantly higher at both time points examined. The patient/guardian questionnaire revealed that azithromycin, with its less frequent administration and shorter duration of treatment, was considered to be both more effective and easier to use than tobramycin.

In the present study, the duration of treatment was regarded as "very satisfactory" by more than three times as many azithromycin-treated patients or guardians as tobramycin-treated patients or guardians $(69.1 \%$ vs $20.5 \%$ respectively), though the difference was less marked when those rating the duration as merely "satisfactory" were included (95\% vs $76.7 \%$ respectively). Similarly, instillation of drops was significantly easier in the azithromycin than in the tobramycin group, and a higher proportion of parents and guardians in the azithromycin group never found difficulty in performing usual daily activities. Although questionnaires of this type cannot provide details on why performing daily activities should be more difficult on tobramycin than on azithromycin, it is not difficult to imagine that instillation of eyedrops morning and evening would be less disruptive to daily family life and children's activities than a requirement to administer drops every 2 hours.

The bacteriological and clinical findings from this study have previously been reported, and the present results extend those findings. ${ }^{12} \mathrm{Clinical}$ cure rate was reduced more rapidly by azithromycin than by tobramycin ( $41 \%$ vs $28.7 \%$ respectively on day $3, P=0.013$ ) and was noninferior at the end of the study $(89.2 \%$ vs $78.2 \%$ respectively at day 7$)$. Resolution of bacterial pathogens, including resistant species, was similar with 
A

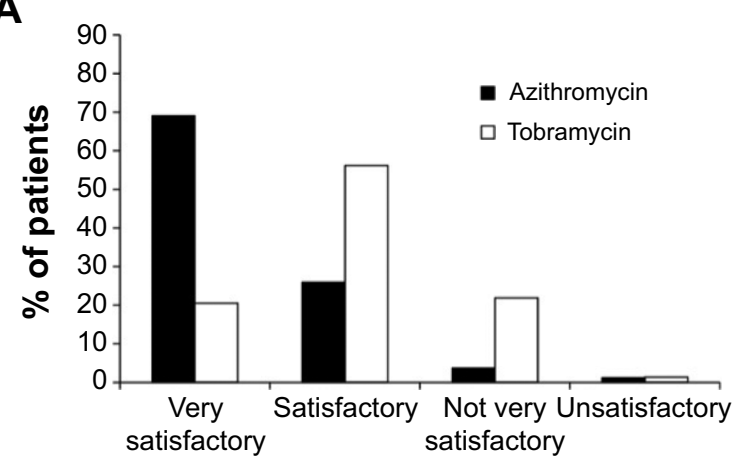

C

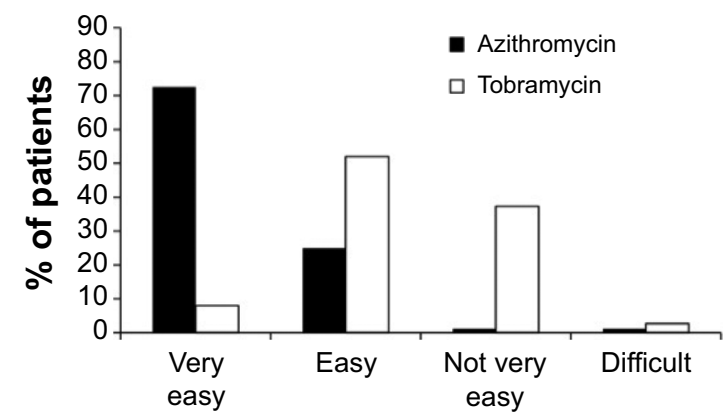

B

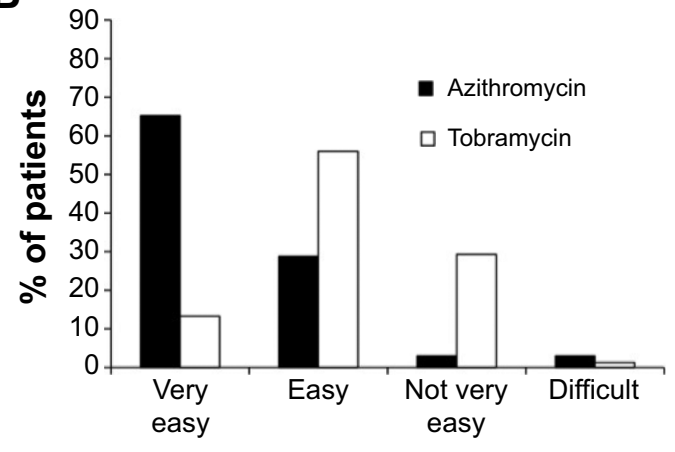

D

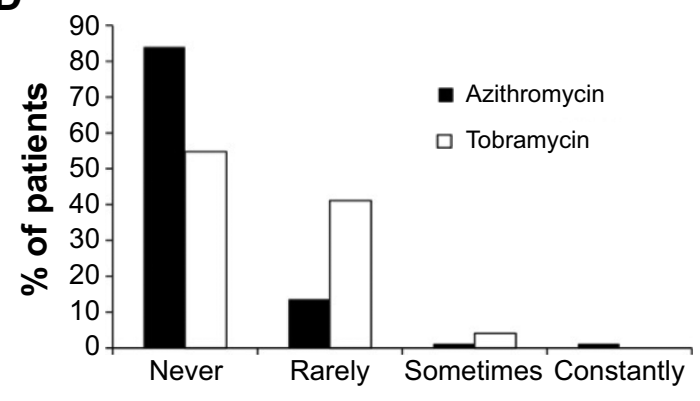

Figure 4 Ease of treatment and impact on daily life.

Notes: $(A)$ Treatment duration $(P<0.00 \mathrm{I})$. (B) Easiness of instilling drops during the day $(P<0.00 \mathrm{I})$. (C) Easiness of respecting the prescribed number of instillations $(P<0.00 \mathrm{I})$. (D) Difficulty of performing usual activities $(P<0.00 \mathrm{I})$. (Full analysis set population: 84 patients in the azithromycin group and 75 patients in the tobramycin group).

the two treatments. As in the present study, the results were broadly equivalent in the sub- 24 months of age subgroup.

Although bacterial conjunctivitis generally resolves without treatment, there are benefits to be gained, particularly in moderate to severe cases, by the more rapid improvements that can be achieved with topical antibiotic treatment. As well as the clinical benefits of avoidance of complications (particularly in younger children), earlier resolution of symptoms, and a reduction in the chance of contagion, nonclinical benefits such as an earlier return to school (and less loss of curriculum) and less disrupted work life for parents should be taken into account. ${ }^{19,20} \mathrm{~A}$ survey of 326 parents of children estimated that $54.2 \%$ of children missed 1.9 days of school and $28.6 \%$ of parents missed a mean of 1.5 days of work during a bout of infective conjunctivitis. ${ }^{15}$
Despite the significant literature on topical antibiotic use in infective conjunctivitis, until relatively recently, there have been few studies on the use of topical ocular antibiotics in children, ${ }^{21}$ particularly newborns and infants who are at particular risk of bacterial conjunctivitis and who can suffer the most serious complications such as ophthalmia neonatorum. The current study recruited patients from hospitals rather than from general practice; since bacterial conjunctivitis in older children is generally managed in a community setting, this study included a significant population of newborns and infants. Because the study included a large population of these younger children (a population frequently underrepresented in similar clinical studies), the results in this group of patients are particularly noteworthy. Bulbar conjunctival hyperemia and purulent discharge were lower in azithromycin- than in

Table 2 Summary of questionnaire results among infants (aged less than 24 months)

\begin{tabular}{lll}
\hline & Azithromycin (N=76) & Tobramycin (N=72) \\
\hline Global treatment efficacy "very satisfactory" or "satisfactory" & $86.8 \%(\mathrm{~N}=46)$ & $77.4 \%(\mathrm{~N}=41)$ \\
Improvement reported in the first two days of treatment & $84.2 \%(\mathrm{~N}=38)$ & $54.8 \%(\mathrm{~N}=31)$ \\
Treatment duration "very satisfactory" or "satisfactory" & $92.9 \%(\mathrm{~N}=42)$ & $70.0 \%(\mathrm{~N}=40)$ \\
Eyedrop instillation during the day "very easy" or "easy" & $97.1 \%(\mathrm{~N}=34)$ & $66.7 \%(\mathrm{~N}=42)$ \\
Respecting the prescribed number of instillations "very easy" or "easy" & $100 \%(\mathrm{~N}=45)$ & $54.8 \%(\mathrm{~N}=42)$ \\
Performing usual activities "never" difficult & $75.6 \%(\mathrm{~N}=4 \mathrm{I})$ & $53.7 \%(\mathrm{~N}=41)$ \\
\hline
\end{tabular}

Note: Full analysis set: azithromycin $(\mathrm{N}=76)$, tobramycin $(\mathrm{N}=72)$. 
tobramycin-treated patients at both day 3 (by 14\% for bulbar hyperemia and $20 \%$ purulent discharge respectively) and day 7 (by $20 \%$ for bulbar hyperemia and $18 \%$ for purulent discharge respectively); such differences are likely to be of clinical significance.

Convenience of use is a factor in promoting persistence and compliance, both of which are important when antibiotics are used to combat infection. Convenience is likely to be even more important in pediatric preparations, where the patient may not understand the significance of the medication. Like the tobramycin eyedrops used in the present study, most antibacterial ophthalmic solutions require instillation up to 8 times each day for 7-10 days. ${ }^{2,22}$ Such a frequency and duration of application inevitably interfere with daily family life and raise significant barriers to good compliance, increasing the burden of illness for the patient and the family as a whole. The more benign dosage regimen of azithromycin 1.5\% (a total of 6 instillations, compared with 36 for tobramycin) is more convenient for use in children. This is particularly the case for babies and infants in whom the instillation can be stressful for both child and parent. A twice-daily dosing regimen (on rising and at bedtime, for example) is likely to fit in with daily family life more easily than more frequent administrations.

Clinical evidence supports the contention that shorter and less frequent courses of antibiotic eyedrops are to be preferred from the compliance standpoint; compliance and satisfaction have been reported to be improved in twice daily versus four times eyedrop regimens in children, ${ }^{17}$ and in younger children (aged 2-9 years), compliance was significantly better with a twice daily fusidic acid regimen than with a 4-6 times daily tobramycin regimen. This is confirmed by studies in other ocular diseases where compliance falls as the number of instillations required increases, with midday instillations being the ones most likely to be omitted, ${ }^{23,24}$ and by studies in children receiving treatment for nonocular infective illnesses. ${ }^{25}$ A positive feature of the present study is the incorporation of a relatively large proportion, indeed a majority, of younger (less than 2 years of age) patients in whom the clinical results and questionnaire responses were not worse than in the patient population as a whole.

Inadequate compliance with a full course of antibiotic therapy is a well-known cause of antibiotic resistance, prolongs illness, and results in unnecessary costs; the longer and more onerous the course of treatment, the greater the probability of noncompliance and the associated risk of microbial resistance. ${ }^{26,27}$ In addition, it is generally well recognized that adherence is better in the early phase of treatment, perhaps because the patient is more aware of their condition; more complex treatment schedules also contribute to imperfect compliance. ${ }^{28}$ As symptoms begin to resolve and patients return to their normal daily activities, their focus on regular use of the drops is likely to diminish, particularly if the duration of treatment is long. ${ }^{23}$ Thus, the less frequent and shorter treatment schedule for azithromycin permitted by its pharmacokinetic properties ${ }^{11,29}$ may contribute to improved adherence and diminished microbial resistance.

The additional results presented here provide an interesting supplement to those in the initial report, ${ }^{12}$ particularly since data regarding the burden of management of purulent conjunctivitis remain very limited. However, a limitation of the study is evident in the relatively low rate of return of questionnaires, which may introduce an element of bias into these results.

In conclusion, the azithromycin formulation used in the present study produced a rapid resolution of clinical signs and symptoms in children with bacterial conjunctivitis. The twice-daily for 3 days regimen was convenient and easy to use and, in particular, fitted in with normal daily life. Such enhanced ease of use and convenience may serve to improve compliance and limit bacterial resistance by encouraging more complete treatment.

\section{Acknowledgments}

John Stolz provided editorial support in the preparation of the manuscript. This support was reimbursed by Laboratoires Théa. The authors acknowledge the contribution of the Azithromycin Pediatric Study Group investigators: Harrtani A, Mustapha University Hospital, Ophthalmology Department, Alger, Algeria; Kaercher T, Ophthalmology, Private Practice, Heidelberg, Germany; Khairallah M, Fattouma Bourguiba University Hospital, Ophthalmology Department, Monastir, Tunisia; Kocyla B, Children's Memorial Health Institute, Ophthalmological Consulting Unit for Children, Warzaw, Poland; Lorenz B, Justus-Liebig University of Giessen, Ophthalmology Department, Giessen, Germany; Mortemousque B, University Hospital of Rennes, Pontchaillou Hospital, Ophthalmology Department, Rennes, France; Murta J, University Hospital of Coimbra, Ophthalmology Department, Coimbra, Portugal; Nezzar H, University Hospital of Clermont-Ferrand, Gabriel Montpied Hospital, Ophthalmology Department, Clermont-Ferrand, France; Nucci P, San Giuseppe Hospital, University Eye Clinic, Ophthalmology Department, Milan, Italy; Salgado-Borges J, S. Sebastiao Hospital, Ophthalmology Department, Santa Maria Da Feria, Portugal; Tataru C, Alcor Ophthalmology Clinic, Bucharest, Romania; Tatineanu M, The Children's Emergency Hospital "Marie Curie", Pediatric Ophthalmology Department, Bucharest, Romania; Voinea L, University Emergency Hospital, Ophthalmology Department, Bucharest, Romania. 


\section{Disclosure}

DB-G and FC are consultants for Alcon, Allergan, Bausch and Lomb, and Laboratoires Théa. However, they did not receive personal fees for this study. DR is an employee of Laboratoires Théa. The authors report no other conflicts of interest in this work.

\section{References}

1. McDonnell PJ. How do general practitioners manage eye disease in the community? Br J Ophthalmol. 1988;72(10):733-736.

2. McCormick M, Fleming D, Charlton J. Morbidity Statistics from General Practice: Fourth National Survey 1991-1992. London: HMSO; 1995.

3. Mah F. Bacterial conjunctivitis in pediatrics and primary care. Pediatr Clin North Am. 2006;53(Suppl 1):7-10.

4. Syed NA, Chandler JW. Bacterial conjunctivitis. In: Tabbara KF, Hyndiuk RA, editors. Infections of the Eye. Vol 8. 2nd ed. Boston, USA: Little, Brown and Co; 1986:69-84.

5. Hovding G. Acute bacterial conjunctivitis. Acta Ophthalmol. 2008; 86(1):5-17.

6. Gigliotti F, Williams WT, Hayden FG, et al. Etiology of acute conjunctivitis in children. J Pediatr. 1981;98(4):531-536.

7. Gross RD, Hoffman RO, Lindsay RN. A comparison of ciprofloxacin and tobramycin in bacterial conjunctivitis in children. Clin Pediatr. 1997; 36(8):435-444.

8. Bertino JS Jr. Impact of antibiotic resistance in the management of ocular infections: the role of current and future antibiotics. Clin Ophthalmol. 2009;3:507-521.

9. Golde KT, Gardiner MF. Bacterial conjunctivitis in children: a current review of pathogens and treatment. Int Ophthalmol Clin. 2011;51(4): 85-92.

10. Sheikh A, Hurwitz B, van Schayck CP, McLean S, Nurmatov U. Antibiotics versus placebo for acute bacterial conjunctivitis. Cochrane Database Syst Rev. 2012;9:CD001211.

11. Garnock-Jones KP. Azithromycin 1.5\% ophthalmic solution: in purulent bacterial or trachomatous conjunctivitis. Drugs. 2012;72(3):361-373.

12. Bremond-Gignac D, Nezzar H, Bianchi PE, et al. Efficacy and safety of azithromycin $1.5 \%$ eye drops in paediatric population with purulent bacterial conjunctivitis. Br J Ophthalmol. 2014;98(6):739-745.

13. Messmer EM. Bakterielle Konjunktivitis - Update zu Diagnose und Therapie. [Bacterial conjunctivitis - diagnosis and therapy update]. Klin Monbl Augenheilkd. 2012;229(5):529-533. German.

14. Jackson WB, Low DE, Dattani D, Whitsitt PF, Leeder RG, MacDougall R. Treatment of acute bacterial conjunctivitis: $1 \%$ fusidic acid viscous drops vs $0.3 \%$ tobramycin drops. Can J Ophthalmol. 2002;37(4):228-237.

Clinical Ophthalmology

\section{Publish your work in this journal}

Clinical Ophthalmology is an international, peer-reviewed journal covering all subspecialties within ophthalmology. Key topics include: Optometry; Visual science; Pharmacology and drug therapy in eye diseases; Basic Sciences; Primary and Secondary eye care; Patient Safety and Quality of Care Improvements. This journal is indexed on Submit your manuscript here: http://www.dovepress.com/clinical-ophthalmology-journal
15. Milazzo G, Papa V, Carstocea B, et al. Topical netilmicin compared with tobramycin in the treatment of external ocular infection. Int J Clin Pharmacol Ther. 1999;37(5):243-248.

16. Protzko E, Bowman L, Abelson M, Shapiro A; AzaSite Clinical Study Group. Phase 3 safety comparisons for $1.0 \%$ azithromycin in polymeric mucoadhesive eye drops versus $0.3 \%$ tobramycin eye drops for bacterial conjunctivitis. Invest Ophthalmol Vis Sci. 2007;48(8):3425-3429.

17. Abelson M, Protzko E, Shapiro A, Garces-Soldana A, Bowman L. A randomized trial assessing the clinical efficacy and microbial eradication of $1 \%$ azithromycin ophthalmic solution vs tobramycin in adult and pediatric subjects with bacterial conjunctivitis. Clin Ophthalmol. 2007;1(2):177-182.

18. Cagle GD, Abshire RI. Quantitative ocular microbiology: a method for the enumeration and identification of bacteria from the skin-lash margin and conjunctiva. Invest Ophthalmol Vis Sci. 1981;20(6):751-757.

19. Gueylard Chenevier D, LeLorier J. A willingness-to-pay assessment of parents' preference for shorter duration treatment of acute otitis media in children. Pharmacoeconomics. 2005;23(12):1243-1255.

20. Rose PW, Ziebland S, Harnden A, Mayon-White R, Mant D; Oxford Childhood Infection Study group (OXCIS). Why do general practitioners prescribe antibiotics for acute infective conjunctivitis in children? Qualitative interviews with GPs and a questionnaire survey of parents and teachers. Fam Pract. 2006;23(2):226-232.

21. Sheikh A, Hurwitz B, van Schayck CP, McLean S, Nurmatov U. Antibiotics versus placebo for acute bacterial conjunctivitis. Cochrane Database Syst Rev. 2012;9:CD001211.

22. Kernt K, Martinez MA, Bertin D, et al. A clinical comparison of two formulations of tobramycin $0.3 \%$ eyedrops in the treatment of acute bacterial conjunctivitis. Eur J Ophthalmol. 2005;15(5):541-549.

23. Rotchford AP, Murphy KM. Compliance with timolol treatment in glaucoma. Eye (Lond). 1998;12 (Pt 2):234-236.

24. Patel SC, Spaeth GL. Compliance in patients prescribed eyedrops for glaucoma. Ophthalmic Surg. 1995;26(3):233-236.

25. Kardas P. Patient compliance with antibiotic treatment for respiratory tract infections. J Antimicrob Chemother. 2002;49(6):897-903.

26. Tenover FC, McGowan JE Jr. Reasons for the emergence of antibiotic resistance. Am J Med Sci. 1996;311(1):9-16.

27. Kardas P, Bishai WR. Compliance in anti-infective medicine. Adv Stud Med. 2006;6:S652-S658.

28. Kass M. Non-compliance to ocular therapy. Ann Ophthalmol. 1978; 10:1244-1245.

29. Lode H, Borner K, Koeppe P, Schaberg T. Azithromycin-review of key chemical, pharmacokinetic and microbiological features. J Antimicrob Chemother. 1996;37(Suppl C):1-8.

\section{Dovepress}

PubMed Central and CAS, and is the official journal of The Society of Clinical Ophthalmology (SCO). The manuscript management system is completely online and includes a very quick and fair peer-review system, which is all easy to use. Visit http://www.dovepress.com/ testimonials.php to read real quotes from published authors. 